William Poole is President of the Federal Reserve Bank of St. Louis. The author thanks Robert Rasche, Senior Vice President and Director of Research, Federal Reserve Bank of St. Louis, for his extensive assistance. The views expressed are the author's and do not necessarily reflect the official positions of the Federal Reserve System.

\section{Monetary Policy Rules?}

\author{
William Poole
}

The J effrey and Kathryn Cole Honors College Lecture Michigan State University

East Lansing, Michigan

A II aspects of our behavior, economic and otherwise, are governed and organized by various rules. The most routine aspects of our lives become unpredictable and even chaotic when not governed by well-defined and generally accepted rules. For example, in the 20th century, every country has adopted a legal rule that governs automobile traffic. In the United States, it is understood that automobiles are driven to the right; in the United Kingdom, the rule is to drive to the left. If, as a U.S. driver, you travel to England and are unaware of the rule for driving or choose to ignore it, it is quite likely that the outcome will be tragic.

In a similar vein, the convention in the United States is to walk to the right. Generally this works well, and pedestrian traffic flows smoothly even along crowded walkways. In some cultures, the rules for pedestrian traffic do not appear to be as clearly understood. There it is common to observe considerable zigging and zagging in dense traffic as pedestrians seek to avoid collisions in the absence of a systematic decision process on how to proceed. The absence of a well-understood convention for pedestrian traffic increases transit times and can result in considerable irritation. Resources, which could be used productively, are wasted.

What is a rule? A rule can be defined as "nothing more than a systematic decision process that uses information in a consistent and predictable way." ${ }^{1}$ The con- cept of a monetary policy rule is the application of this principle in the implementation of monetary policy by a central bank. Why, then, the question mark in my title? There is a large body of economics literature on the rules-versus-discretion debate over monetary policy. I do not intend to analyze, or psychoanalyze, this debate here. I especially do not intend to address the political side of this debate - whether it would be desirable for a national legislature to enact a monetary policy rule to be executed by the country's central bank. Rather, my purpose is to examine what we mean by a monetary policy rule followed by a central bank, and to examine what we know about the construction, or design, of the rule.

I will first discuss some general issues in the design of rules. Next, I'll discuss what monetary policy can achieve-we need to be clear about what a policy rule is supposed to accomplish. I'll also review how the Federal Reserve conducts monetary policy today to provide the background necessary to understand the practical design issues for a monetary rule. My final topic will be the critical requirements that must underlie any satisfactory rule. That will bring me to our current understanding of a practical rule.

Before digging into this topic further, however, I want to emphasize that the views I express here reflect my thinking and do not necessarily reflect official Federal Reserve views. Bob Rasche, until recently a member of the Department of Economics at M ichigan State University, is really a co-author of this lecture; he deserves credit for its strengths and I'll accept responsibility for its errors.

SOME GENERAL

\section{CONSIDERATIONS IN} DESIGNING RULES

How are rules constructed? In many cases, rules govern our interaction with

\footnotetext{
1 Allan H. Meltzer, "Commentary: The Role of Judgment and Discretion in the Conduct of Monetary Policy," Changing Capital Markets: Implications for Monetary Policy, Federal Reserve Bank of Kansas City, 1993, p. 223.
} 
the environment, and the optimal rule can be established as the solution to a welldefined engineering problem. Given advances in technology, many rules, formerly executed manually, are now performed by automatic devices. For example, thermostats that control the heat in our homes and autopilots that control the progress of aircraft embody such rules. A second type of rule governs our interactions with others. When the absence of well-defined rules of behavior or the failure to conform to a convention seriously harms the welfare of others, the government implements a rule by law and imposes penalties for disobedience. You will be apprehended quickly if you insist on driving on the right side of the road in England.

A third type of rule involves the formulation of policy decisions. Here, a systematic decision-making process is complicated because individuals and market participants observe or infer the actions of the policymakers and adjust their behavior in ways that work to their benefit, given their understanding of the policy regime. This is the type of problem faced by monetary policy decision-makers.

This point is so important that it deserves special emphasis. Compare two card games: solitaire and poker. Solitaire is a game against nature - the characteristics of a deck of cards. Those characteristics do not change from one day to the next. Poker is a game against intelligent agents. The players may change from one day to the next. Players learn about each other's playing styles over time and change how they play. Designing an optimal rule, or strategy, for poker is a much more difficult problem than designing an optimal rule for playing solitaire.

Monetary policy, needless to say, is more like poker than solitaire. The goal of monetary policy, however, is to make the economy better off, not to go home at the end of the evening with your friends' money. The fact is, though, that monetary policy affects interest rates, people make or lose money from interest-rate fluctuations, and therefore, the markets are constantly trying to forecast the next monetary policy adjustment. This interaction-policymakers trying to understand and interpret mar- kets, and markets trying to predict what policymakers will do-makes the task of designing an optimal monetary policy rule a very, very difficult problem.

\section{WHAT CAN MONETARY POLICY ACHIEVE?}

At the beginning of the 1960s, economists generally believed that central banks could and should be significant players in the effort to achieve multiple social objectives: low inflation, high growth, low unemployment and low nominal interest rates. In addition, the Federal Reserve was expected to contribute to specific efforts such as encouraging balanced payments with the rest of the world and a strong housing sector.

The notion that central banks can provide a low-cost, over-the-counter "aspirin" that will alleviate almost any ill that a society can face is no longer credible. There is now a consensus among economists and central bankers that the only long-run effect a monetary authority can have on an economy is to determine the sustained, or trend, rate of inflation. That rate will result from the rate at which the monetary authority injects money into the economy.

The view that price stability depends upon monetary conditions has a long history in monetary economics. Indeed, the basic proposition that the amount of money determines the price level originated long before economics was recognized as a discipline. Simply put, I would like to note that in the late 19th and early 20th centuries, economists were precise about the nature of the connection between money and the general price level. Irving Fisher, among others, made important contributions to monetary theory long before the $G$ reat Depression. This idea- that the general price level and its rate of increase depends primarily on the level of the money stock and its rate of increase- fell out of favor with the rise of Keynesian analysis in the 1930 s and 1940s. The idea was revived in the 1950 s by Milton Friedman, who has lived to win the intellectual battle that sustained inflation is everywhere and always will be a monetary phenomenon. 
A consensus also exists that erratic monetary policy has sometimes produced instabilities in the economy. Most analysts now agree that Federal Reserve actions contributed significantly to the severity of the Great Depression in the United States. Monetary policies can make the economy either more or less stable. It is generally acknowledged that at least some- I think a lot- of the credit for the stability of the U.S. economy during the past 15 years is due to Federal Reserve policy under Chairmen Paul Volcker and Alan Greenspan. Finally, it is generally accepted that central banks are responsible for acting as a lender of last resort in the event of a generalized liquidity crisis to maintain the soundness and function of the payments mechanism. Most economists accept the view that prompt Federal Reserve actions in October 1987, after the stock market crash and again last September after the Russian default, were appropriate policy interventions. Of course, we continue to debate the appropriate extent of Fed actions to all eviate a liquidity crisis-indeed, even what truly qualifies as a liquidity crisisbut that debate does not detract from acceptance of the general principle that a central bank response is desirable when the crisis is severe.

The problem of designing monetary policy to achieve sustained low inflation and more, rather than less, stability is far from trivial. We know much less about this task than we should. At this point, no consensus exists on the size or reliability of the short-run impact of monetary policy on an economy. A considerable amount of professional opinion, the general popular feeling, and financial-market commentary hold that monetary policy actions initially affect output, unemployment, and real interest rates, even though the long-run impact on these real variables is nil. Research efforts to quantify these initial effects, however, have failed to provide precise measures of the impact, and at least one school of thought maintains that such short-run effects are negligible.

To judge monetary policy and central bankers, we must concentrate on what they can reasonably be expected to achieve, given our current state of knowledge. There is a compelling case, I believe, that the success or failure of monetary policy must be judged first and foremost by whether a central bank is able to achieve a low-inflation environment on a sustained basis. That environment is, in turn, conducive to maximum growth and efficient utilization of the resources available to a society. High growth and efficient utilization of resources depend on government policies beyond the central bank's control. That fact, however, does not change the proposition that a central bank's contribution should be judged primarily by the average rate of inflation, and secondarily by the stability, or lack thereof, of the overall economy.

By this standard, the history of the second half of the 20th century, in the United States and in other countries, is not kind to central bankers. For a short period during the late 1950s and early 1960s, the U.S. economy (for all practical purposes) experienced price stability. The return to low inflation following the Korean War was consistent with prior U.S. experience that inflation was a wartime phenomenon. During peacetime, citizens generally were unconcerned about inflation.

Periodically, the Gallup poll has asked, "W hat do you think is the most important problem facing the country today?" One of the response choices was: "Inflation or the high cost of living." In 1956, several years after the end of the Korean conflict, only 13 percent of respondents indicated this concern. By 1964, the fraction of respondents selecting this response had dropped to six percent.

Sixteen years later, in 1980, the economy was at the peak of the inflation that had started during the Vietnam War. Inflation as measured by the consumer price index (CPI) had reached double-digits. Short-term interest rates exceeded 20 percent. People came to understand that this inflation could not be attributed to war; the Vietnam War had ended by the mid1970s, but inflation persisted and indeed rose for the rest of the decade. The fraction of Gallup poll respondents who ranked 
inflation as the N 0.1 problem facing the economy rose almost continuously - from 27 percent in 1972, to 47 percent in 1976, to 61 percent in 1980. All segments of society shared this concern.

Today, the price tranquility of the late 1950 s and early 1960s has been reestablished, both in the United States and in most other industrial countries. In the United States, annual inflation during each year from 1983 through 1989 was close to 4 percent. With the exception of a brief increase just before and during the Persian Gulf conflict in 1991, the inflation rate has declined steadily to the point where the economy last year was close to practical price stability. By 1993, only 1 percent of Gallup poll respondents ranked inflation as the most important problem facing the country. An article in the Wall Street Journal last month reflected on a survey conducted by Yale U niversity economist Robert Shiller:2

It is now widely accepted that high rates of inflation can damage an economy by distorting markets, undermining public faith in government and forcing all sorts of wasted effort. Mr. Shiller's 1996 survey found that $84 \%$ of the public-though only $46 \%$ of economists-felt that preventing high inflation was as important as preventing drug abuse or deterioration of schools. A return of inflation would be jarring: The last time the Labor Department checked, only one in five major union contracts included an automatic cost-of-living adjustment, down from $60 \%$ in the early 1980 s. A spread of the Japanese-style deflationary spiral, in which falling prices exacerbate a recession, would also be painful.

But right now, the U.S. has neither. Instead, it is experiencing an absence of inflation. Without inflation, the old-fashioned notion that young couples can buy a house and grow into their mortgage payments with everbigger paychecks may soon be as quaint as a telephone with a dial. And retirees living off interest on certificates of deposit and government bonds will be shocked when their securities mature to see how far interest rates have fallen as inflation ebbs. Already, rates on six-month certificates of deposit are down to an average of $4 \%$, according to BanxQuote Inc., and some big banks are paying little more than $1 \%$ on regular savings accounts.

Clearly, our economy-indeed many aspects of our broader society-is deeply affected by inflation and by the absence of inflation. The public has no doubt, and I have no doubt, that the absence of inflation is better. A critical question facing all of us at the present time is whether the inflation experience of the past 16 years will be sustained. Or, will this period ultimately be viewed in history as a wonderful stroke of good luck - an anomaly in an age of otherwise nearly permanent inflation?

\section{HOW DOES THE FED CONDUCT MONETARY POLICY TODAY?}

The Federal Reserve has practiced a consistent approach to the implementation of monetary policy at least since the mid1980s. Monetary policy decisions are the responsibility of the Federal Open Market Committee (FOMC). The FOMC consists of the seven governors of the Federal Reserve System, the president of the Federal Reserve Bank of N ew York, and four of the presidents of the remaining 11 regional Federal Reserve Banks, on a rotating basis. This committee meets eight times a year, to discuss the current state of the economy and the prospects for near-term developments. The committee then votes on instructions - the Directive to the System Open Market Account Manager- that specify a target value for the federal funds interest rate. The federal funds rate is the rate at which depository institutions borrow and lend to each other their reserve balances on the books of the Federal Reserve Banks. The Fed usually refers 
to the target federal funds rate as the intended rate.

Once these instructions have been approved, it is the responsibility of the staff of the Open Market Desk at the Federal Reserve Bank of New York, in consultation with the Chairman and members of the Open Market Committee, to keep the actual funds rate close to the intended rate. The Desk proceeds by buying and selling U.S. government securities for the Federal Reserve's account, or by engaging in transactions that are the practical equivalent of buying and selling government securities. When the Account Manager desires to offset market forces that are driving the funds rate above the intended rate set by the FOMC, the Desk purchases securities in the open market for the Fed's account. When the Account Manager desires to offset market forces that are driving the funds rate below the intended rate, the Desk sells securities into the market from the Fed's account. The direct result of such purchases and sales is that the amount of currency and/or balances of depositories at the Federal Reserve Banks is increased or decreased.

This approach to implementing monetary policy is not new. Exactly the same procedures were employed during the late 1960s and throughout the 1970s, the period of rising inflation. Therefore, there is no guarantee that the tactics of monetary policy, as currently practiced by the FOMC, will be successful in maintaining a low-inflation environment; the exact same procedures delivered the Vietnam-era inflation.

\section{KEY DESIGN}

\section{CONSIDERATIONS FOR A} MONETARY POLICY RULE

We must address two critical issues in the process of designing a rule for monetary policy. First, the rule must take into account the fact that the individuals' regarding the Fed's future actions are an important determinant of economic outcomes. Second, the rule must be very explicit about the information the FOMC uses to determine how to change the intended federal funds rate.
An important development- if not the important intellectual development throughout the past 25 years in our understanding of how the macroeconomy works- is the recognition that expectations play a central role in affecting economic behavior. Previously, to the extent that expectations were considered at all, they were treated in a rather mechanical fashion. Contemporary analyses now postulate that individuals do not simply look to past economic outcomes to project the future path of important conditions like the inflation rate. Instead, individuals understand that it is in their self-interest to contemplate seriously what path the Federal Reserve likely will pursue for monetary policy and to align their expectations about future inflation with their perceptions of Fed actions.

Such a role for expectations is not just an element of elegant and stylized economic theories. Expectations influence market activities day in and day out. Traders in the federal funds futures contracts on the Chicago Board of Trade, for example, pore over testimony and speeches of the Chairman and Federal Reserve officials, searching for hints about whether the FOMC will change the intended federal funds rate at its next meeting, or some meeting after that. Financial markets can gyrate widely in response to a remark whose interpretation is contrary to the prevailing impression.

A monetary policy rule must take into account these market expectations and speculations. The goal should be that interest rates and other market prices will respond to objective information about the economy - the same information that monetary policy itself depends on. The fact that markets so often respond to comments and speeches by Fed officials indicates that the markets today are not evaluating monetary policy in the context of a well-articulated and well-understood monetary rule. The problem is a deep and difficult one. The Fed does not know how to specify its monetary policy decisions so that the market can look at the same data the Fed looks at and arrive at the same conclusion. I make this statement not by way of any criticism of my Fed colleagues or staff, but 
simply as an honest statement of how things are today. We apply our best judgment to the task and do not rely on a formal rule, because we do not have a formal rule we trust.

My point here is that a critical part of designing a rule is dealing with the interaction of the Fed and the markets. Given this interaction, an important first feature of any rule must be that it is formulated in a systematic fashion and can be communicated easily to the public. A rule the public does not understand will not work satisfactorily because policy changes resulting from application of the rule will constantly take the markets by surprise. The public will not and should not accept a procedure that creates policy changes that seem totally unpredictable and, therefore, arbitrary and capricious.

Second, a policy rule must have the correct long-run properties. A rule that, if followed religiously, would permit inflation to rise or fall to unacceptable levels would obviously be deficient. This aspect of designing a rule is, fortunately, relatively straightforward.

Third, I think it is desirable, though I confess substantial uncertainty on this point, that a rule rely heavily on the market itself. On the whole, markets do a good job in allocating resources efficiently and making judgments about things that are difficult to predict. I think a rule will work best if it can establish a solid and predictable base for monetary policy, leaving maximum room for markets to set interest rates and other prices. F or example, if we knew of a direct way to set the rate of inflation to zero directly, then market interest rates could be free to rise and fall as credit demands rise and fall.

\section{MONETARY POLICY RULES}

Now I'm down to the bottom line of this lecture- what might an actual monetary policy rule look like?

The place to begin is with the policy rule advocated by Milton Friedman, among others, starting during the 1950 s. The long-standing controversy over mone- tary rules derives in large part from this particular rule. Friedman's proposed rule was that the Federal Reserve should establish a constant rate of growth for the stock of money and maintain that growth rate no matter what emerged from the state of the economy. Friedman's opponents argued that, should the Fed adopt such a rule, it would default on its responsibilities to stabilize cyclical fluctuations of the economy. They felt that such stabilization required that the Fed exercise discretion in the conduct of monetary policy. Friedman countered that historically the Fed was the principal cause of cyclical fluctuations in the economy and that much of the desired stabilization of the economy would be achieved if money growth were constant.

Nothing in the modern concept of a monetary policy rule requires that the Fed pursue a policy invariant to the state of the economy. The restrictions imposed on Fed decision-making by the monetary-rule process, as defined here, only require that decisions to change or not change the intended federal funds rate repeatedly incorporate the same information and respond to that information in the same way.

Critics of the rule approach argue that the Fed must consider all available information about the economy. There is nothing in the concept of a monetary rule, however, that precludes the FOMC from reaching its decisions based on a wide variety of information. All that is required is that the same information be considered and incorporated into the decision-making process in the same fashion each time the intended federal funds rate level is reassessed. Neither the data consulted, nor the weight placed on particular pieces of information, should be altered in repeated decisions. Furthermore, operating under a monetary rule requires that the basis for deciding whether to change the intended federal funds rate be clearly communicated to the public. Everyone should be able to make informed predictions about the future course of policy, given knowledge of the same facts about the state of the economy. 
The rule calling for a constant growth rate of the money stock has many desirable features:

- It is easy for the public to understand.

- The rate of inflation cannot take off toward plus infinity or minus infinity if money growth is held constant.

- Interest rates are free to fluctuate in response to changing market conditions.

The Friedman rule, however, has not gained general acceptance. One reason why is that the term "money" must be defined in an acceptable way if the rule is to work and be easily understood by the public. Many, and perhaps most, economists today believe that changes in the amount of money demanded by the public are of sufficient size and duration that keeping the money stock on a steady path will likely lead to much larger fluctuations in the inflation rate and level of economic activity than we'd like. The better way of stating this point is to say that a central bank using its best judgment can beat the performance of the Friedman rule, and that this claim is well demonstrated by the Fed's performance since it began to attack inflation in 1979. There are other criticisms of the Friedman rule. My purpose here, however, is not to review this whole debate but to discuss the issue of rules more generally.

Others-especially Allan M eltzer and Bennett McCallum - have worked on variants of the Friedman rule. These are quantity-based rules that yield a changing growth rate of the money stock or the monetary base. The research is promising and deserves more attention than it gets.

Another approach is an interest-rate rule, in contrast to the quantity rules just discussed. The policy rule for interest rates that has been discussed most often for several years now was proposed by Stanford economist John Taylor in 1993. $\mathrm{His}$ rule is an attractive one to consider because it is so closely linked to traditional Fed practice in setting an intended federal funds rate.
Taylor proposed that the federal funds rate be determined by a rule with three basic terms in it. First, the funds rate should equal an estimate of the economy's real rate of interest at a zero rate of inflation plus the Fed's target rate of inflation. For example, with an estimate of an equilibrium real rate of interest of 2 percent, and a long-run target rate of inflation of 1 percent, the base rate for the federal funds rate would be 3 percent.

The second term in the Taylor rule calls for an adjustment to the intended federal funds rate when the inflation rate deviates from the FOMC's target inflation rate. Continuing with the illustration that the target inflation rate is 1 percent, if the actual inflation rate is 2 percent, then the inflation deviation is 1 percentage point. The Taylor rule multiplies that deviation by a specified coefficient and adds the product to the intended federal funds rate. For example, if the coefficient is 1.5 , then the inflation deviation of 1 percentage point yields an intended federal funds rate that is higher by 1.5 percentage points.

Taylor has emphasized the importance of having a coefficient on the inflation deviation term that is higher than 1.0. If the coefficient is below 1.0, then an increase in inflation will call forth an increase in the intended federal funds rate that is smaller than the increase in inflation. That means that the real rate of interest would fall when inflation rises, which is a recipe for a neverending increase in inflation. Everyone agrees that the coefficient on the inflation deviation needs to be above 1.0, but how much above is unknown at this time. There also is an issue of how to define the inflation rate- what index to use and what time period. Using the inflation rate over the last month would introduce a great deal of random noise into the federal funds rate set by the rule; using the inflation rate averaged over the last five years would yield a rule that responds too slowly to changing conditions. The optimal length of the averaging period is not known at this time. Using an inflation forecast might be better, but whose forecast?

The third term in the Taylor rule is the deviation of real gross domestic product 
(GDP) from the path of potential GDP. We can call this quantity the GDP deviation. Several ideas lie behind this term. One is that if the Fed were to follow a money growth rule in an economy in which the problems with that rule did not exist, then interest rates would rise and fall as credit demands rise and fall with the strength of the economy. In this sense, the Taylor rule mimics the behavior of interest rates under a constant-money-growth rule. More generally, it seems sensible that if the economy is booming- running well above potential - then interest rates should be somewhat higher to check the excessive pressure on available labor and capital resources. If the economy is slack - operating below potential - then interest rates should be somewhat lower to encourage greater utilization of available resources.

The argument for a term in the policy rule reflecting the GDP deviation is attractive. The optimal size of the coefficient on this term is not known, however. Whether the federal funds rate should change by an amount equal to 0.5 , or 2.0 , or some other number times the GDP deviation is being investigated. Moreover, potential GDP is not an observable variable.

Although different researchers have different ideas about which is the best method of measuring potential GDP, I do not regard this issue as critical, because an error here will not send the economy off permanently in one direction or the other. The rule will be stabilizing, though not perfect, if potential GDP is misestimated. The size of the coefficient on the GDP deviation is an important issue, however, as it determines how stabilizing the rule is likely to be. This is a complicated mattertoo large a coefficient might induce economic cycles around potential GDP and too small a coefficient might permit sustained departures from a desirable path that would tend to destabilize the rate of inflation.

Taylor argued that the behavior of the federal funds rate incorporated in his rule is a reasonable approximation to the actual process of adjustment of the funds rate targets the FOMC used between 1987 and 1993-a period during which monetary policy was quite successful. But his rule is much more than a simple effort to fit the data. It incorporates important and sound theoretical principles that need to be followed if monetary policy is to be successful. As I have al ready emphasized, however, there is much we do not understand about the optimal construction of a monetary policy rule. We should be wary about accepting coefficients that seem to come out of a small slice of history, no matter how successful policy was during that period. Every empirical economist is all too familiar with the phenomenon of a great model fit during a sample period, followed by utter disillusionment with the performance of the model outside the sample period.

As you can imagine, there are numerous potential problems with the Taylor rule; I've mentioned just a few. But these problems also are problems with the current conduct of monetary policy. Gauging the current interest rate against the equilibrium real rate of interest is an important part of our job today, but we don't know what the equilibrium real rate is in precise numerical terms. We need to judge the current level of the economy against its potential, but we don't know in precise numerical terms what that potential is. Criticizing the Taylor rule, or any other rule, for such reasons does not help solve the problems policymakers face, nor does it make a convincing case that what we do now is better than following an imperfect rule.

The Taylor rule has figured more prominently than other proposed rules in recent discussions of monetary policy rules. Undoubtedly, interest in the Taylor rule reflects the fact that the current implementation of monetary policy around the globe focuses on manipulating a short-term interest rate. Thus, the adoption of a Taylor-type rule would not require the Federal Reserve to alter its operating procedures; the Taylor rule is an effort to formalize the decision-making process that generates the operating instructions in the Fed's current practice.

Another approach to monetary policy, known as inflation targeting, has been instituted by the central banks in several foreign countries. ${ }^{3}$ The practice, which 
varies from country to country, started with the Reserve Bank of N ew Zealand, and has been adopted by the Bank of Canada, the Bank of England, the Bank of Finland, the Swedish Riksbank, and the Reserve Bank of Australia. These central banks announce in advance their policy objective for an inflation rate. This announcement reflects a public commitment of the central bank to the policy objective. In none of these cases has the central bank specified the decision rule that it will use to achieve the stated objective. In no market economy can the central bank control the inflation rate or the price level directly. It must intervene in some market to manipulate a price or a quantity to steer the economy toward the desired objective- whether this objective is announced or not. The variable manipulated by the central bank is defined as the policy instrument. The monetary rule indicates the process by which the central bank adjusts the policy instrument when information on the performance of the economy relative to its policy objective is received. Thus, merely announcing a policy objective in terms of the inflation rate does not assure that the central bank is operating under a monetary policy rule. However, I believe that it is desirable for central banks to be clear about their objectives, and in this regard I believe that inflation targeting is a desirable practice.

\section{THE PATH TO PROGRESS IN MONETARY POLICY DECISIONS}

I believe that the Taylor rule is a promising approach to better understanding monetary policy. From what I have al ready said, however, it should be clear that I do not believe that this rule is ready for adoption. We need a lot more research.

Two areas deserve special attention. One concerns a role for monetary aggregates and the second a role for market interest rates, or some other piece of market information.

As a general proposition, we can extract information from markets by studying both prices and quantities. The total neglect of information about the monetary aggregates in the Taylor rule opens up a natural avenue to extend the rule. This is not the place to present current research results, especially since I don't have any of this kind. I am simply saying that, given all the evidence supporting Milton Friedman's proposition that "inflation is now and everywhere a monetary phenomenon," it seems to me that we ignore the behavior of the monetary aggregates at our peril.

Obviously, interest rates reflect market expectations about the future. Might we incorporate rates in the rule in some fashion? The idea is intriguing, but there is a circularity problem because it appears that the bond and money markets respond significantly to changes in Fed policy and to changes in expectations about Fed policy. The more confidence the market has in the Fed, the more the market will concentrate on what the Fed is doing and the less the market will concentrate on fundamentals other than the Fed. Consider an analogy: If you are an investor but know little about investing, it makes sense to choose your investments by observing the decisions of an investor known for his superior performance. This strategy is likely to work better for you than concentrating on investment fundamentals themselves, which by assumption, you may not understand very well. The market watches the Fed because the Fed is well informed and because the Fed is the dominant player in the money market.

The more confidence the market has in the Fed's willingness to do whatever is necessary to maintain low inflation, the more sense it makes for the market to concentrate on the Fed's actions rather than forming an independent judgment about future inflation prospects. Therefore, the Fed cannot use the behavior of interest rates in the bond market to provide useful information on how it should adjust the federal funds rate.

If, however, the Fed is able to adopt a precise rule in the future, which is based on information everyone can observe- such as that employed in Taylor's rule- then there may well be a place for an interest rate 
term in the rule. If the market could be confident that the Fed would change the federal funds rate, only in response to the observed inflation rate and the GDP deviation (and whatever other observable information the Fed included in the rule), then market forecasts would be incorporated in interest rates. Adding an interest rate term to the rule would be a way to add forecasts to the rule, which, in principle, should make it work better than a rule based solely on past data.

\section{CONCLUDING REMARKS}

The concept of a monetary rule is attractive for many reasons. To repeat the definition offered at the beginning of this lecture, a rule is "nothing more than a systematic decision-making process that uses information in a consistent and predictable way." Operating under a monetary rule imposes accountability and transparency upon a central bank. It requires that the policymakers be specific about the rationale behind their policy actions. The record of the decisions will then contain information from which future decision-makers can learn.

A policy rule ought not be considered irrevocable or unchangeable. At any time, our understanding of the short-run impact of monetary policy on the economy is imperfect. Policymakers necessarily operate within constraints imposed by the current state of knowledge and should not be blamed for outcomes that are impossible to avoid given that knowledge. One of the benefits of a policy rule is that a historical record will exist that can be analyzed, and from this analysis we can obtain an understanding of why past policy actions did not produce the intended effects. The knowledge gained from such analysis can and should be incorporated into the formulation of future policy rules. Possible changes in the rule should be studied and debated. When the analysis indicates that the rule can be improved, the Fed should announce the changes in advance and explain the rationale for them.

A policy rule also provides the surest method to pass the accumulated knowledge about the effective operation of monetary policy to future generations. This, after all, is how engineers, using engineering theory and observation of skilled human pilots, constructed autopilots. These devices had to be tested and refined, and the process took time. The devices are subject to continuous improvement. Under normal flying conditions, an autopilot now does a better job than a human pilot at keeping an aircraft on its desired course. As I have emphasized, designing a monetary rule is a difficult task intellectually, but it seems obvious to me that this is the path we must travel.

In short, pursuing the path of developing and then adhering to a rule provides the best approach- perhaps the only approach - to improving the practice of monetary policy over the long run. Washington, D.C., September 1998. 